\title{
"SER ESSA TERRA: SÃO PAULO CIDADE INDÍGENA": EXPOSIÇÃO NO MEMORIAL DA RESISTÊNCIA TRATA DA (RE)EXISTÊNCIA DOS POVOS ORIGINÁRIOS NA CAPITAL PAULISTA
}

\author{
CASÉ ANGATU ${ }^{1}$ \\ UESC/UFSB, BRASIL
}

\begin{abstract}
RESUMO: São Paulo é também uma Cidade Indígena, repleta de memórias, territoriedades, identidades e vivências passadas e atuais dos Povos Originários. No entanto, muitos ainda se surpreendem ou até negam a possibilidade de a cidade ser também Indígena. Ao findar de 2018 um coletivo de pessoas com esta percepção se reuniu para criar uma Exposição. Logo na conversa inicial ficou decidido que seria organizada tendo como protagonistas as Populações Indigenas das diferentes etnias na cidade e região. Foi assim que surgiu a Exposição "Ser Essa Terra: São Paulo Cidade Indígena", inaugurada em 24/11/2018 e localizada no Memorial da Resistência na capital paulista. É possivel que esta tenha sido a primeira exposição possuindo como eixo a presença dos diversos Povos Originários na cidade de São Paulo e, ao mesmo tempo, protagonizada por cerca de vinte indígenas, com a consultoria curatorial de também um indígena: Casé Angatu Xukuru Tupinambá. A mediação curatorial ficou ao encargo de Daniel Kairoz e Marília Bonas. A exposição contou com fotos, sons, textos, depoimentos, vídeos, objetos, artefatos, artesanatos e produtos do manejo originário, revelando a experiência de Ser Indígena na capital paulistana.
\end{abstract}

PALAVRAS-CHAVE: Povos Indígenas, Cidade de São Paulo, Protagonismos

ABSTRACT: São Paulo is also an Indigenous City, full of memories, territories, identities and past and present experiences of the Originating Peoples. However, many are still surprised or even deny the possibility that the city is also indigenous. By the end of 2018 a collective of people with this perception gathered to create an Exhibition. In the initial conversation it was decided that it would be organized with the protagonists of the Indigenous Populations of the different ethnic groups in the city and region. This is how the "Ser Essa Terra: São Paulo Indigenous City" Exhibition, opened on 11/24/2018, was located at the Resistencia Memorial in São Paulo. It is possible that this was the first exhibition having as its axis the presence of the various Originating Peoples in the city of São Paulo and, at the same time, led by about twenty indigenous people, with the curatorial consultancy of also an indigenous: Casé Angatu Xukuru Tupinambá. The curatorial mediation was in charge of Daniel Kairoz and Marilia Bonas. The exhibition featured photos, sounds, texts, testimonials, videos, objects, artifacts, crafts and products from the original management, revealing the experience of Being Indigenous in São Paulo.

KEYWORDS: Indigenous Peoples, City of São Paulo, Protagonisms

\footnotetext{
${ }^{1}$ Casé Angatu - Carlos José Ferreira dos Santos - é Indígena Morador no Território Tupinambá de Olivença - Aldeia Taba Gwarïnï Atã (Ilhéus/BA). Doutor pela FAU/USP, leciona na Universidade Estadual Santa Cruz-UESC (Ilhéus/BA) e na Pós-Graduação Ensino Relações Étnico Raciais - Universidade Federal Sul Bahia-PPGER/UFSB (Itabuna/BA). E-mail: angatucase@gmail.com trata da (re)existência dos povos originários na capital paulista. Espaço Ameríndio, Porto Alegre, v. 14, n. 1, p. 118-137, jan./jul. 2020.
} 


\title{
Uma exposição protagonizada por Índios é mais do que uma exposição
}

Ainda causa estranhamento quando falamos que a Cidade de São Paulo tem Povos Originários entre seus moradores. Do mesmo modo, alguns se surpreendem ou até negam a possibilidade de a Capital Paulista ser também uma Cidade Indígena, composta por memórias, identidades e territoriedades originárias. Certas pessoas desconhecem até mesmo a existência de Aldeias no município paulistano.

No entanto, pondero que São Paulo nunca deixou de ser também o que denomino com a indígena Tabatatyba (Aldeia de vários Povos) e outrora denominada como Piratininga (Peixe Seco). Andando pela cidade, além dos indígenas das Aldeias Guarani localizadas na cidade, percebemos que muitos de seus moradores, incluindo os que vivem nas ruas, praças, viadutos, tem suas ancestralidades ligadas aos Povos Originários de etnias forçadas a saírem de suas terras natais. Presença do mesmo modo observada nos nomes de rios, ruas, lugares, bairros e arredores.

Somo a estas ponderações os dados do censo do Instituto Brasileiro de Geografia e Estatística (IBGE) para 2010 . Segundo os dados censitários, o município é até um dos que mais possuem população indígena no Brasil com 12.977 Índios para aquela data.

Porém, acredito que o desconhecimento sobre esta presença étnica originária na cidade é em alguns casos inconscientes e, por vezes, proposital e historicamente constituído. Entendo que existe ao longo da história local, uma tentativa de apagar e silenciar certos grupos sociais e étnicos na cidade, dentre eles a população indígena.

Como analiso no livro Nem Tudo Era Italiano - São Paulo e Pobreza (1890-1915) isto ocorre pelo menos desde a virada do século XIX para XX:

\begin{abstract}
Havia um projeto de europeização arquitetônica, urbanística e populacional. Buscava-se a apagar "qualquer traço caipira, caboclo, indígena e negro da cidade". Buscava-se uma "limpeza sociocultural" perseguindo práticas e espaços de vivencias das camadas populacionais nacionais nas áreas mais centrais e suas adjacências. Buscava-se a formação de um mercado de trabalho supostamente controlado. (ANGATU, 2017a, p. 200)
\end{abstract}

Penso que na atualidade ainda persiste esta forma de atuar sobre a cidade por parte de uma certa elite local e de alguns agentes do poder público paulistano. Entretanto, sempre existem as diferentes formas de resistência e (re)existência daqueles que alguns desejam silenciar ou invisibilizar.

Como pondero no Posfácio à quarta edição do livro citado anteriormente: 
Mas assim como na virada do século XIX para o $\mathrm{XX}$, quando (re)existiram múltiplas vivências das camadas populares, as (re)existências socioculturais continuaram vivas. Como antes, os projetos de parte dos detentores do poder econômico não se consolidaram como um todo. A cidade das camadas populares nacionais (indígena, afrodescendente, cabocla, caipira, migrante) continuou e continuará a (re)existir. (ANGATU, 2017a, p. 200 2001) $)^{2}$

Estas foram algumas das percepções que conduziram um coletivo de pessoas a se reunirem no dia 18 de setembro de 2018. Inicialmente este coletivo foi formado por mim, Marília Bonas, Daniel Kairoz e Marília Gallmeister. ${ }^{3}$

Este grupo começou a se formar a partir do Curso de Extensão que organizo e leciono em alguns espaços da cidade denominado: "Histórias, Culturas Indígenas e a Cidade de São Paulo". ${ }^{4}$ Marília Bonas que realizou o curso e como Coordenadora Técnica do Memorial da Resistência de São Paulo me convidou para organizar uma exposição acerca da presença indígena no município. Convidei então Daniel Kairoz e Marília Gallmeister que também realizaram o curso para fazerem parte desta organização.

A ideia basilar era pensar a possibilidade de uma exposição tratando da resistência e (re)existência indígena na cidade de São Paulo. O intuito era dizer às pessoas: "silêncio! Escutem os sons nativos que vem do profundo das angas (almas) indígenas que povoam a polifônica capital paulista que alguns dizem não ter alma. Olhem à sua volta e enxerguem a presença indígena na multifacetada cidade de São Paulo. Vejam imagens que alguns queriam invisibilizadas e ouçam sons que, apesar das tentativas de silenciamento, brotam dos Povos Originários que circulam e ecoam de dentro da Paulicéia Desvairada."

O que se encontra entre aspas no parágrafo acima é parte de uma coletânea de frases que escrevi e foram expostas em painéis na exposição "Ser Essa Terra: São Paulo Cidade Indígena”. Quanto à terminologia Paulicéia Desvairada vale esclarecer que é o nome de um livro de poesias escrito por Mário de Andrade em 1922 - mesmo ano da Semana de Arte Moderna. No livro São Paulo é retratada como uma cidade cosmopolita

\footnotetext{
${ }^{2} \mathrm{Na}$ perspectiva de que os Povos Originários não ficaram numa posição somente passiva, indicamos a leitura de: AYRA e ANGATU, 2018 e 2019; CASTRO, 2006 e 2011; ARRUTI, 1995 e 2002; CUNHA, 1992, 2009, 2012, 2013 e 16/02/2017; ALMEIDA, 2003 e 2010; OLIVEIRA, 2000, 2004 e 2006; MONTEIRO, 1995 e 2001; CALEFFI, 2003.

${ }^{3}$ Marília Bonas: Museóloga e Coordenadora Técnica da Memorial da Resistência de São Paulo; Daniel Kairoz: Editor-Coreógrafo-Revisor-Diagramador na Phármakon e Coreógrafo no Terreyro Coreográfico; e Marília Gallmeister: Arquiteta e Urbanista da Associação Teat(r)o Oficina Uzyna Uzona e do Projeto Coletivo Terreyro Coreográfico.

${ }^{4}$ Este Curso possui uma trajetória que ultrapassa 10 anos, procurando apresentar formas de abordagens, conceitos, metodologias, conteúdos, fontes, sabedorias e questionamentos acerca da presença indígena na história do Brasil, formação da sociedade brasileira e, especialmente, na constituição identitária da cidade de São Paulo em seus vários territórios. Já administrei o Curso no Instituo Bixiga, Sesc 24 de Maio, Sesc Centro de Pesquisa e Instituto Fundação Cultural Ema Gordon Klabin, entre outros espaços. 
que se industrializava e urbanizava rapidamente, formada por uma população heterogênea.

Logo de início ficou decidida que a organização da exposição seria protagonizada pelos próprios indígenas moradores da capital paulista e seus arredores. Aquele coletivo inicial da organização da exposição partia do princípio que são os próprios Povos Originários os sujeitos do processo de decolonização e superação das visões tradicionais que negam suas presenças, identidades e memórias.

Compreendemos que ainda os conhecimentos
produzidos pelas academias são, em muitos casos,
dominados por uma postura de colonialidade, sendo
também uma forma de poder. (...) Procuramos fortalecer
os caminhos da decolonialidade a partir dos saberes,
conhecimentos, nossas linguagens e vivências como
forma de também fortalecer a resistência e
(re)existência indígena, quilombola, negra, gênero e de
todos que lutam "por um mundo onde caibam vários
mundos". Podemos até fazer arte, ciência, produzir
conhecimentos e cultura, vestidos e nos espaços
acadêmicos. Mas para alcançarmos certos saberes, os
saberes ancestrais e das/dos Encantadas/Encantados
que moram na Natureza e habitam a essência de nossos
Corpos, ao menos para chegar perto destes saberes, é
preciso ter a Anga Catupei (Alma Nua/ Despida/Limpa)
(AYRA, 2019a, p. 232) ${ }^{5}$

Logo após a primeira reunião do coletivo inicial organizador da exposição realizaram-se os contatos com indígenas pertencentes aos Povos Originários moradores na cidade e região. Foram convidados a construírem a exposição: Fulni-ô, Guarani Mbya, Kaimbé, Kariboka, KaririXocó, Pankararé, Pankararu, Pankaré, Tupi-Guarani, Tupinambá e WassuCocal.

Aqui vale ponderar que os contatos com as etnias foram realizados através das informações oferecidas pelos próprios indígenas. Buscou-se convidar a totalidade das etnias moradoras na cidade e região. Porém, é possível que indígenas de outros Povos moradores em São Paulo não tenham participado da organização da exposição porque não conseguimos contato, apesar do desejo pela ampla participação.

Deste modo, participaram: Alaide Pankararé, Maria Pankararé, Pedro Pankararé, Clarisse Pankararu, Maria Lídia Pankararu, Ivone Pankararu, Avani Fulni-Ô, Txairon Fulni-Ô, Alex Kaimbé, Dhevan Gwyrá Dju, Índio Badaróss, Jaguaretê, Jera Guarani, Pajé Guaíra, Pajé Laguna,

\footnotetext{
${ }^{5}$ As palavras decolonização e decolonialidade são utilizadas aqui a partir das leituras dos seguintes autores: BALLESTRIN, 2013; BRAH, 2011; CASTRO-GÓMEZ e GROSFOGUEL, 2007; FANON, 2010; GROSFOGUEL, 2008 e 2016; LANDER, 2005; MIGNOLO, 2005; SANTOS, 2010; SPIVAK, 2010; WALSH, 2013. 
Paulo Wassu Cocal, Sonia Barbosa Tamikuã Txih, Wiryçà Kariri Xocó, entre outros que contribuíram direta ou indiretamente com a exposição.

Estes indígenas, além de discutirem conceitualmente a exposição, fizeram junto às suas comunidades pré-seleções de fotos, sons, depoimentos, textos, vídeos, objetos artísticos, artefatos, artesanatos e produtos do manejo indígena que entrariam na mostra. ${ }^{6}$

O espaço escolhido para a exposição foi o Memorial da Resistência de São Paulo, vinculado à Associação Pinacoteca e Cultura - APAC e localizado no Largo General Osório, 66 - São Paulo/SP. A opção por este espaço ocorreu porque lá atua como Coordenadora Técnica uma das pessoas do coletivo que incialmente organizou a exposição: Marília Bonas.

Além disso, a preferência pelo Memorial da Resistência decorreu da importância política e sociocultural daquele espaço, conforme explica o seu próprio site:

(...) é uma instituição dedicada à preservação de referências das memórias da resistência e da repressão políticas do Brasil republicano (1889 à atualidade) por meio da musealização de parte do edifício que foi sede, durante o período de 1940 a 1983, do Departamento Estadual de Ordem Política e Social de São Paulo Deops/SP, uma das polícias políticas mais truculentas do país, principalmente durante 0 regime militar. (...) Desde 2009 o Memorial da Resistência de São Paulo é Membro Institucional da Coalizão Internacional de Sítios de Consciência, uma rede mundial que agrega instituições constituídas em lugares históricos dedicados à preservação das memórias de eventos passados de luta pela justiça e à reflexão do seu legado na atualidade (MEMORIAL DA RESISTÊNCIA, 24/10/2019).

Apesar de ter como um de seus eixos a resistência, foi a primeira vez que o Memorial da Resistência abrigou especificamente uma exposição tratando da (re)existência indígena, protagonizada pelos próprios Povos Originários da cidade de São Paulo. Aproveito para agradecer a direção e todos os funcionários do Memorial por possibilitarem a realização da Exposição "Ser Essa Terra: São Paulo Cidade Indígena".

\footnotetext{
${ }^{6}$ Estas denominações são as utilizadas, com variações, conforme o vocabulário de cada Povo Indígena. SANTOS, Carlos José Ferreira dos. "Ser essa terra: São Paulo cidade Indígena": exposição no memorial da resistência trata da (re)existência dos povos originários na capital paulista. Espaço Ameríndio, Porto Alegre, v. 14, n. 1, p. 118-137, jan./jul. 2020.
} 


\section{SEER ESSA TEERRA são paulo cicladle indígena}

de 24 de novembro 2018 a 22 de abril 2019

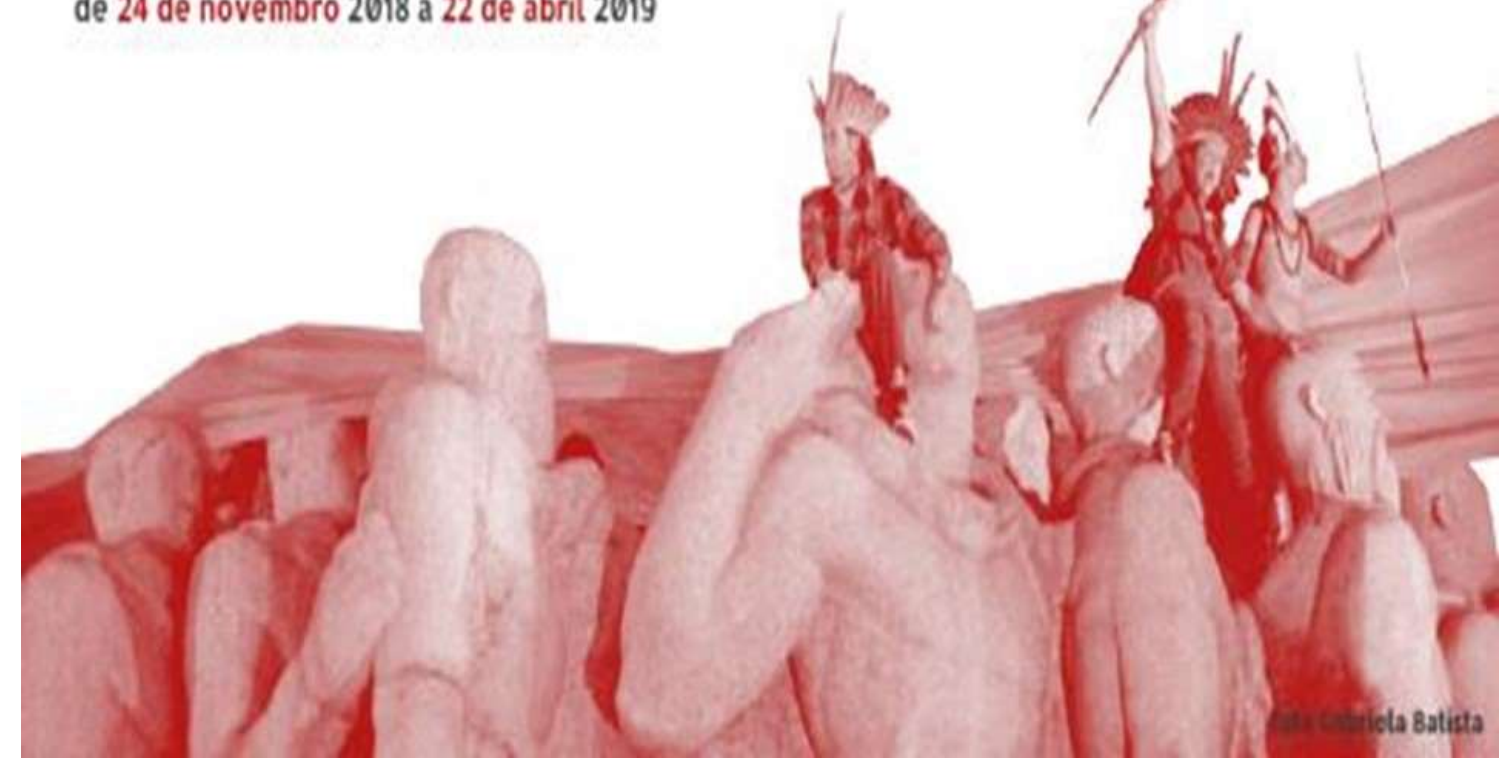

Foram três meses de intensa organização e participação dos Povos Originário até a inauguração que ocorreu no dia 24 de novembro de 2018 com rituais indígenas de abertura. A ideia de rituais originários na abertura relacionava-se profundamente com a concepção da exposição: colocar os saberes e a cosmologia originária como condutora, curando a cegueira e surdez em relação à presença dos Povos Indígenas em São Paulo. Por isto também a utilização da palavra curatoria ao invés de curadoria como é comum empregar para aqueles que organizam uma exposição. Assim, curatoria seria uma forma de tentar curar, ao modo indígena, a cegueira e surdez relativas aos Povos Originários na constituição da cidade.

Mais do que uma exposição, a intenção era realizar um constante ritual para a anga (alma) dos que fossem visitar o "Ser Essa Terra: São Paulo Cidade Indígena". No dia da inauguração (24 de novembro de 2018) o saguão de entrada e central do Memorial da Resistência ficou repleto de não indígenas, indígenas, energias da natureza encantada e ancestrais. Foram expostos artesanatos, produtos de manuseio indígenas, faixas e realizados rituais de cada um dos Povos presentes. 
Fotografia 2: Abertura da Exposição em 24 de novembro de 2018. Ocorreram cantorias, danças e falas sobre a importância da exposição, presença indígena na cidade e sobre a luta dos Povos Originários. Local: saguão de entrada do Memorial da Resistência.

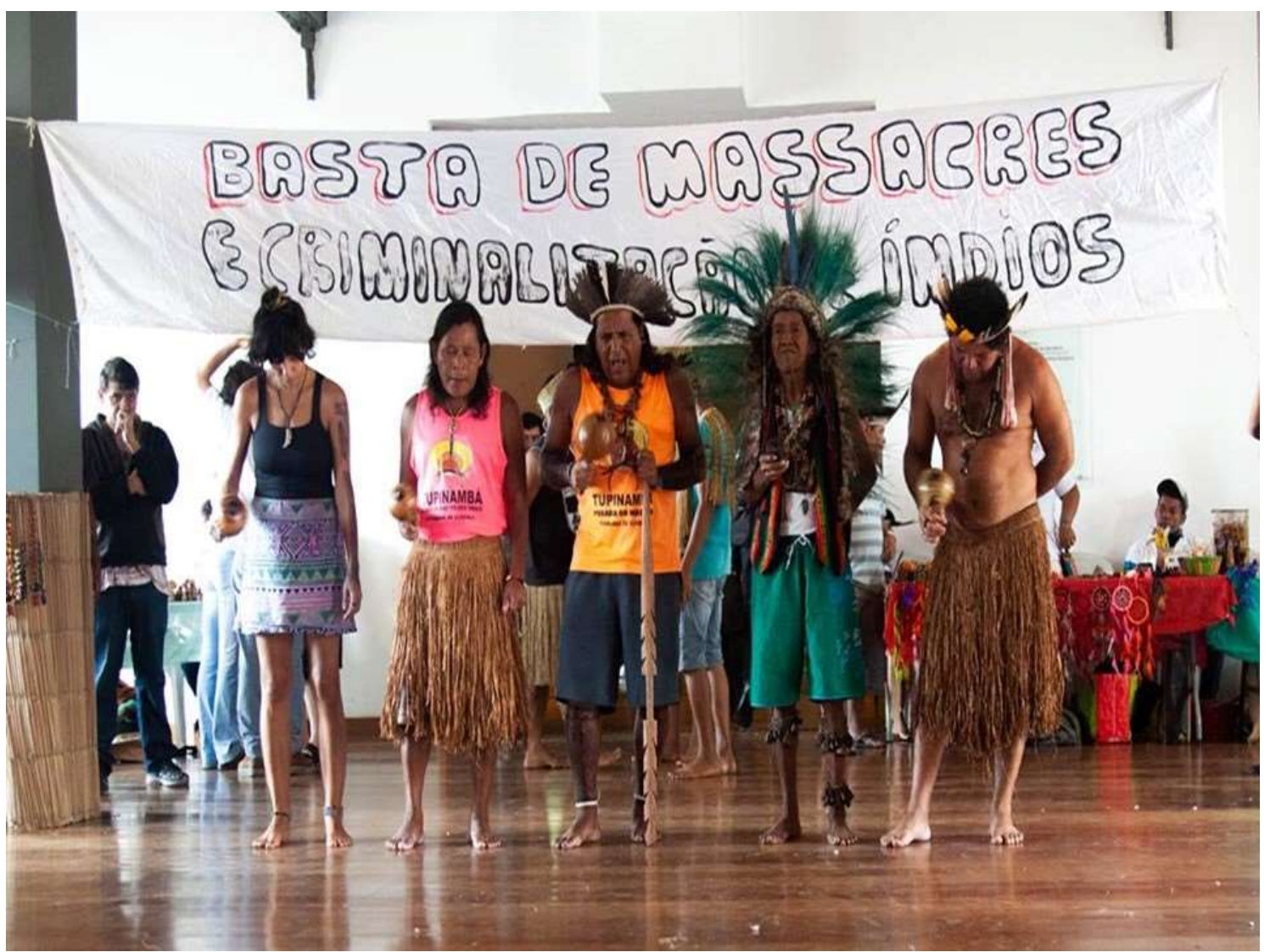

Autoria: Mauricio Pinheiro (24 de novembro de 2018)

A exposição tinha depoimentos, imagens e objetos - em sua maioria captados pela própria população indígena -, revelando a experiência de ser Índio em São Paulo, resistindo e (re)existindo a um processo histórico de tentativas de apagamentos e silenciamentos e que muitos desconhecem. O espaço da exposição foi composto por dois corredores e um núcleo central com os temas: Apagamento, Resistência e $(R e)$ Existência. Todos os espaços cobertos de imagens, objetos, textos e depoimentos em vídeos.

A Equipe do Goma Oficina, responsável pela produção, identidade visual, sinalização e ilustração da exposição, descreveu da seguinte forma a exposição:

A identidade visual foi desenvolvida com o intuito de traduzir a urgência das falas dos povos indígenas expressas nos painéis e pilares do espaço expositivo. A tipografia escolhida foi a Allerta e Allerta Stencil, cujos caracteres foram minuciosamente projetados para serem compreendidos de uma maneira mais rápida: como seu próprio nome diz, um alerta. Foram utilizadas as cores brancas, cinza chumbo e vermelho urucum nas 
tipografias e nos fundos dos painéis, dando destaque ao conteúdo escrito da exposição - a voz dos povos indígenas - e invocando o caráter de urgência inerente à luta indígena (GOMA OFICINA, 24/10/2019)

Fotografia 3: Um dos painéis da exposição.

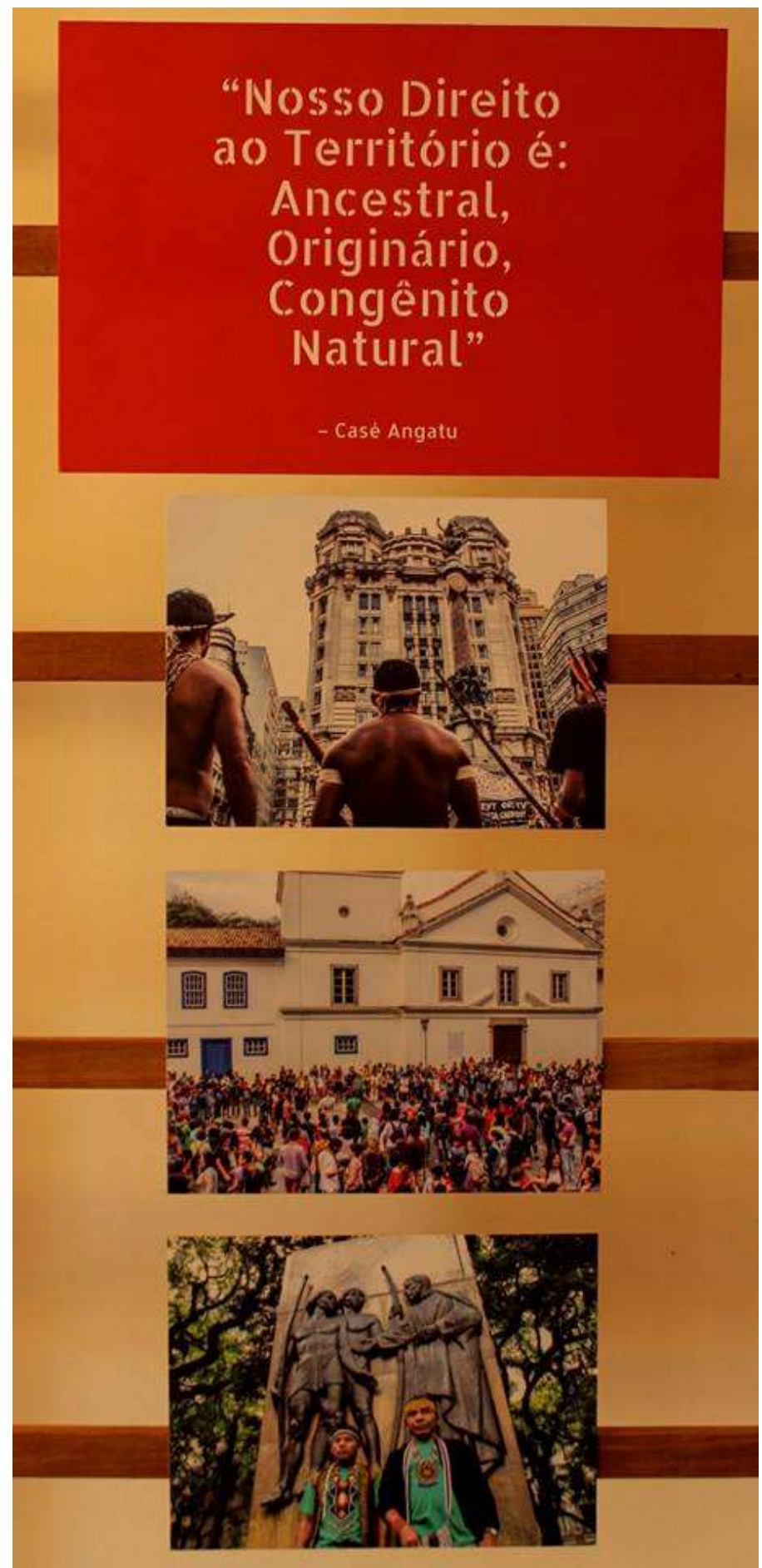

Autoria: Mauricio Pinheiro (24 de novembro de 2018) 
A Exposição ficou no $3^{\circ}$ andar do Memorial da Resistência e deveria terminar em 22 de abril de 2019. Porém, a grande procura fez com que ela fosse prorrogada até 22 de julho de 2019.

É possível até que esta tenha sido a primeira exposição possuindo como fundamento a presença dos diversos Povos Originários na capital paulista e, ao mesmo tempo, protagonizada por cerca de vinte indígenas, com a consultoria curatorial de também um indígena.

$\mathrm{Na}$ sequência apresento o texto que serviu de fundamento para a exposição.

\section{São Paulo é uma cidade indígena}

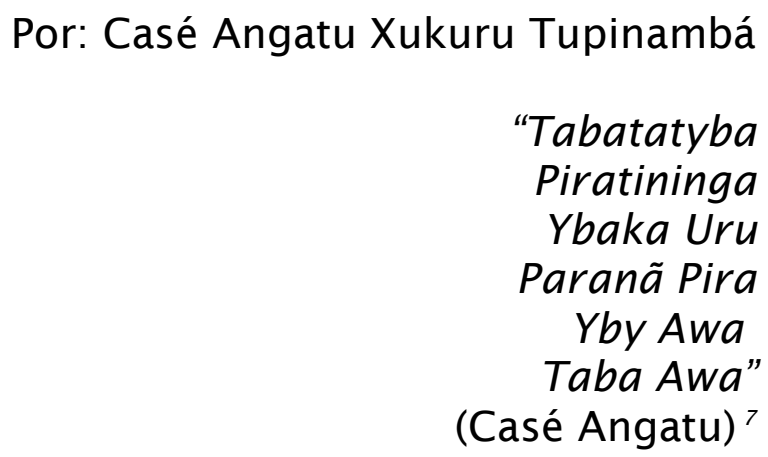

\section{Indigenamente decolonial}

As palavras que seguem partem de nossos saberes ancestrais e das forças encantadas da natureza presentes na luta pelos Direitos do Povos Originários, especialmente o Direito ao Território, Alteridade e Autonomia.

Somos antes de tudo Indígenas que caminhamos com nossa ancestralidade e compromisso com nosso Povo. Procuramos fortalecer os caminhos da decolonialidade a partir de nossos saberes, linguagens e vivências, efetivando a resistência e (re)existência Indígena e de todos que lutam "por um mundo onde caibam vários mundos".

Esta postura não significa que todos nossos saberes ancestrais e da encantada natureza serão revelados. Para alcançarmos estes saberes que moram na Natureza e habitam nossa essência, ao menos para chegarmos perto deles, precisamos ter Anga Catupei (Alma Nua/Despida/Limpa).

\section{ÎE’ ENGA AWA: Fala de Índio que desejam silenciar e apagar}

As palavras são essenciais para as culturas e memórias indígenas e estão presentes em diferentes linguagens que não se restringem à escrita

\footnotetext{
7 "Povoado de Povos de várias Tabas / Peixe Seco / Pássaro do Céu / Peixe do Mar / Gente da Terra / Cidade é do Povo" (Casé Angatu - OBS: esta "tradução" não é ao pé da letra e sim uma interpretação) 
ou à fala. São expressões que aparecem em nossos cantos, olhares, gestos, moradia, maneiras de alimentar, corpo, anga (alma), pinturas, colares, cocares, formas de se relacionar com a natureza, plantar, colher, pescar, rituais, curas, sonhos e nos silêncios indígenas.

Linguagens que são 'advindas de memórias ancestrais inatingíveis pelas palavras escritas por mais cuidadosas que sejam. Quando nós índios estamos na natureza não ficamos sozinhos. Ouvimos as palavras de nossos ancestrais e das/dos Encantadas/Encantados naturais. Os Parentes mortos e vivos emitem suas mensagens através das Matas (Caipora), Plantas (Jurema), Águas (Yara), Bichos (Soo), Céu (Ybaka), Sol (Guarassy), Lua (Îacy): o Sagrado. Conhecemos os sons e silêncios da natureza e deles surgem: îe' enga awa (fala de índio).

Esta é a forma como lidamos com nossas vidas e nos relacionamos com a natureza. Não éramos donos da terra antes dos invasores chegarem em 1500, mas sim a própria terra, porque somos parte da natureza. Não queremos a terra como propriedade e mercadoria para ser explorada, mas para nos relacionarmos. Nela estão nossos Ancestrais e as/os Encantadas/Encantados. Em nosso ser natural não temos o princípio de acumulação e exploração do trabalho ou da natureza.

Quando nos perguntam: "pra que Índio quer terra se não produz?" - respondemos que nossa forma de ser e nos relacionarmos com a natureza é cheia de encantamentos e de profundo respeito. Assim, a terra se torna território. Queremos a terra porque somos ela própria: eis aqui parte do que alguns chamam de cosmologia indígena.

$\mathrm{Na}$ natureza sagrada estão nossas/nossos Encantadas/Encantados, Ancestrais e Espiritualidade. Por isso nosso direito ao Território não é porque o pensamos como propriedade, mas por ser um Direito Ancestral, Sagrado, Congênito e Natural porque Somos a Terra pela qual lutamos, trabalhamos e nos amamos: o mel da terra. É um Direito que precede o direito à propriedade privada.

Esta é a energia vital que nos faz resistir e (re)existir há cinco séculos contínuos de genocídios e etnocídios. Carregamos em nossos corpos, vivências e angas (almas) um outro mundo possível de mútuo respeito entre os humanos e a natureza. Quando fazemos nossos rituais é para Ïacy, Tupã, Encantadas e Ancestrais estarem conosco e ramearmos juntos porque nós somos eles.

Porém, são mais de cinco séculos de violações de nossos Direitos Originários. Essa transgressão é um dos traços mais marcantes e cruéis das relações entre o estado e as elites brasileiras com as populações originárias. Sentimos que nossos corpos, rituais, cosmologias e formas de viver são, natural e espontaneamente, opostos aos interesses dos donos do poder econômico e político que negam nosso Direito ao Território e nossa autonomia enquanto Povos.

Nossa forma de ser quando em sua natureza e o Direito ao Território que possuímos ao que tudo indica é antimercadológico, não atende aos interesses desenvolvimentistas do agronegócio, dos grandes pecuaristas, do setor energético, das empresas mineradora nacionais e internacionais, dentre outras razões. Por isso tentam há mais de 500 anos 
apagar e silenciar nossa presença na história, sociedade, identidade e memória do que se chama de Brasil.

Do mesmo modo, buscam negar nossa existência e direitos assinalando que ou já não existimos mais ou precisamos nos integrar à sociedade nacional. É comum assinalar que todos os povos possuem dinâmica cultural e, portanto, não estão congelados em seus processos históricos. Entretanto, quando muitos tratam de Povos Originários a impressão que fica é: "para ser Índio é necessário ter conservado os traços socioculturais e genéticos existentes nos primeiros séculos da colonização - século XVI".

Qualquer diferença em relação a estes traços idealizados serve como argumentação para descaracterizar a indianidade de um Povo Originário e, como consequência, negar o direito ao Território. Por isso pensamos que a tentativa de congelar nossa presença na formação nacional somente nos primeiros séculos da colonização, bem como não considerar nossa dinâmica cultural, é uma forma de negar o direito à terra e buscar apagar nossa presença.

Essa intenção tem marcado continuamente as formas pelas quais ocorrem as transgressões de nossos direitos, as diferenciadas maneiras de racismo e violências. Por um lado, observa-se uma busca por "assimilar" e "civilizar" as populações indígenas - o que chamamos de tentativas de etnocídio completo ou apagamento de nossa presença; por outro lado, a procura por criminalizar e eliminar fisicamente as populações originárias - o que denominamos de tentativa de genocídio total.

\section{São Paulo que sempre será indigenamente Piratininga}

São exemplares na procura de concretizar o etnocídio ou apagamento as tentativas de: catequização e evangelização; "integração e assimilação" à "sociedade" e "desenvolvimento" nacional. Estas foram práticas que estiveram também presentes na história da Cidade de São Paulo, desde sua chamada "Fundação" (25/01/1554), posterior elevação à Vila (1558), à Cidade (1711) e durante a denominada "Segunda Fundação da Cidade" (1872) - expressão usada para referir-se às transformações que ocorreram na cidade durante a gestão pública de João Teodoro (1872-1875)

Os Aldeamentos Jesuíticos da cidade, considerados como dos seus marcos fundantes, na nossa compreensão, eram, antes de tudo, Aldeamentos Indígenas que constituíram seus territórios e do entorno. Eram ao todo 12 Aldeamentos Indígenas: Pinheiros, São Miguel de Ururaí, Barueri, Carapicuíba, Nossa Senhora da Conceição dos Guarulhos, Embu, São José, Escada, Itaquaquecetuba, Itapecerica, Peruíbe, Queluz.

Esta tentativa de apagamento de nossa presença na história da cidade continuou através das práticas da Coroa Portuguesa e posteriormente do Império. Talvez isto ocorrido porque tinham vergonha de admitir que a aclamada figura considerada como "heroica" do 
Bandeirante paulista era também de caçador e mercenário do trabalho escravo indígena. Em São Paulo utilizou-se do trabalho escravo indígena por um longo período.

$\mathrm{Na}$ virada do século XIX para XX, durante a chamada segunda fundação da cidade de São Paulo (1872), o poder público, buscando branquear sua população, perseguiu vivências socioculturais, tradições e territórios populares que remetiam à presença indígena, negra, caipira, cabocla na futura metrópole. Havia um projeto de europeização arquitetônica, urbanística e populacional dos grupos à frente do poder público. Buscava-se a apagar "qualquer traço indígena, caipira, caboclo, negro da cidade" (ANGATU, 2017a, p. 200). Ocorria então uma tentativa de "limpeza sociocultural" e étnica, algo que marca até a atualidade a ação dos grupos à frente do poder público local.

A partir das décadas de 1930/1940 iniciou-se um grande fluxo de migração. Eram legiões de migrantes nordestinos e de vários interiores deste país. Em grande parte, eram expulsos da terra pela violência dos que se dizem seus donos. A cidade de 887.810 habitantes em 1930 atingiu em trinta anos uma população de 3.781.446 moradores (ANGATU, 2008, p. 189). Por estes números poderíamos chamar de uma nova fundação de São Paulo. Porém, a elite local, decerto, não via com bons olhos estes migrantes que em 1980 tornaram-se 50,90\% da população. Segundo o IBGE daquele ano (1980), o município com uma população de 8.493.226 pessoas tinha 4.323.444 moradores não naturais da cidade.

Migrantes em muitos casos formados por indígenas banidos de suas terras naquilo que denominamos de uma verdadeira diáspora indígena. Trouxeram e fortaleceram as características de vivências, tradições, ancestralidades originárias. Em decorrência da desigualdade econômica e social, fruto de um sistema que acumula riquezas nas mãos de poucos, estes migrantes, por vezes indígenas, repovoaram a cidade em suas periferias, favelas, cortiços, ruas e praças.

Esta migração ainda continua - particularmente a nordestina -, segundo o IBGE (2010), e se soma aos indígenas que na cidade já moravam, fazendo de São Paulo o $4^{\circ}$ município com maior população indígena (população absoluta) no Brasil: 12.977 índios. Atualmente estima-se que a população indígena da cidade chegue a 21 mil.

Por isto consideramos que muitos dos moradores desta cidade incluindo os que vivem nas ruas, praças, viadutos - tem suas ancestralidades ligadas aos Povos Indígenas que foram expulsos ou forçados a saírem de suas terras natais. Também são (re)existentes a mais de cinco séculos de violências iniciadas pelas invasões europeias. Eles são nossos assycueras (irmãs e irmãos) que ainda continuam sofrendo expulsões a partir das ações do poder público local

Esta rápida trajetória nos permite ponderar e entender porque afirmamos que São Paulo é uma cidade indígena. Presença que se faz sentir nos nomes de seus rios: Tamanduateí, Tietê, Saracura. Nos nomes de muitas de suas ruas, lugares, bairros e arredores: Anhanguera, Anhangabaú, Aricanduva, Biritiba, Butantã, Cambuci, Carapicuiba, Cotia, Embu, Embu-Guaçu, Grajaú, Guaianases, Guararema, Guarulhos, Curuçá, 
Grajaú, Ipiranga, Itaquera, Itapevi, Itaquaquecetuba, Itapecerica, Jabaquara, Jaguará, Jacuí, Jaguaré, Jaraguá, Juquitiba, Mairiporã, M’Boi Mirim, Moema, Morumbi, Paissandu, Pacaembu, Piqueri, Pirapora, Piratininga, Pirituba, Mooca, Tatuapé, Tucuruvi, entre outros.

\section{Povos Indígenas: $(\mathrm{Re})$ existência resistente}

Ao mesmo tempo, historicamente contra as populações indígenas que se recusam à "assimilação", "civilização" e catequização (o que chamamos de tentativas de etnocídio), ocorreram as chamadas "guerras justas", marcadas por um processo secular e ainda existente de criminalizações e violências. Essas ações acontecem de forma velada e mesmo autorizadas pelo Estado e sua justiça, desde a coroa portuguesa até a atualidade.

Em nome de "guerras justas" comete-se um sistemático processo de genocídio e prisões. Um exemplo dessas fortes repressões genocidas e que possui profundas relações com a cidade de São Paulo foi a que se abateu em relação às populações indígenas que participaram da chamada "Confederação dos Tamoios", entre 1554 e 1567. A repressão foi tão violenta que levou muitos a considerarem os Tupinambás como extintos.

Mas este massacre não foi o único na história do Brasil. A Comissão da Verdade, encarregada de investigar os crimes cometidos pelo governo ou agentes da Ditadura Militar e Civil brasileira (1964 e 1985), chegou a calcular que foram cerca de 8 mil índios mortos durante este período. 0 que acontece na atualidade com os Guarani Kaiowá no Mato Grosso do Sul, além de outros valiosos Povos, é uma demonstração da perenidade desse processo e como os mandatários do poder político e econômico atuam contra nós.

No entanto, e ao mesmo tempo, sempre existiram diversas formas de (re)existências. Somos também protagonistas de nossas histórias: conformando, reelaborando e/ou resistindo há mais de cinco séculos de violações. Apesar de sermos criminalizados, atacados, feridos, presos e mortos, fazemos a autodemarcação dos nossos Territórios através de retomadas. Fazemos aquilo que o Estado e a justiça deveriam fazer até por um princípio constitucional.

Outra demonstração de nosso protagonismo revela-se quando alguns Povos considerados como extintos apresentam-se como indígenas, lutando pelo ancestral direito à terra, tais como os Povos Murá, Guató, Tupinambá e Charrua. Os dados censitários do IBGE também são reveladores desta (re)existência, pois assinalam que a população indígena no Brasil está crescendo não só pela natividade, mas também pelo auto reconhecimento, chamado por nós de fortalecimento da indianidade. Segundo os dados do IBGE, em 2010 existiam no Brasil 305 Povos Indígenas, falando 274 línguas. Apesar de pensamos que estes números são maiores, assinalam como ocorreram (re)existências realizadas de forma silenciosa ou de modo claro: espiritual e corporalmente. 
Somos sim, vítimas constantes do racismo, negação de direitos e violências, por vezes autorizadas pelo Estado e mesmo pela justiça. Precisamos de garantias às nossas Alteridades e Territórios. Entretanto, nossa luta, como nossa vida, é ritual e por isso nos pintamos, usamos nossos adornos, cantamos, rameamos e (re)existimos há cinco séculos. Nosso misticismo e força advém da natureza encantada, dos ancestrais e anciões.

A nossa luta pelo Território é a luta pelo sagrado e quando deixarmos esta forma física humana ... encantaremos e continuaremos a habitar a grande maloca que é a natureza. Seremos ancestrais de kuñatãs, kurumins, kuñas e awas que espalharam nossas sementes. Falaremos com eles pelos sons da natureza ... por um arco íris/arco-íris ou através de uma pequena yapy - gota de orvalho.

\section{Considerações finais}

Acredito que a exposição concretizou de forma intensa o objetivo de contribuir para a superação dos silêncios e invisibilidades existentes em relação à presença indígena na cidade de São Paulo. Para isso foi fundamental contar com o protagonismo dos Povos Originários em sua conceituação e montagem.

Uma das dificuldades iniciais foi justamente buscar esta participação de representantes dos diferentes Povos presentes na cidade e em seus arredores. Acredito que, neste sentido, a exposição materializou este caminho porque contou com cerca de vinte indígenas de diferentes etnias como protagonistas para sua realização.

Como salientamos anteriormente, é possível que foi a primeira exposição organizadas por indígenas expondo a presença dos Povos Originários na constituição identitária e territorial da capital paulista. Ou seja, um evento em que os indígenas não foram somente objetos e sim sujeitos participativos da sua organização.

Assim, acredito que oferecemos novas contribuições no sentido de repensar as representações museológicas ou artisticas quando tratam dos Povos Originários. Os objetos, fotografias, vídeos, oralidades, falas, músicas, pinturas e as disposições das mesmas foram escolhidas e realizadas atendendo àqueles que tiveram suas culturas e vivências representadas. Pela minha percepção a partir da frequência de indígenas, especialmente na sua inauguração no dia em 24 de novembro de 2018 , acredito que a exposição repercutiu positivamente entre os originários porque contemplou a sua presença como protagonista de suas histórias.

Claro que existiram percalços dificultando o protagonismo indígena. Entre eles destaco que seria importante a presença indígena para monitorar as visitas à exposição. Isto não ocorreu por falta de condições financeiras, no sentido de superar os custos para esta participação.

Outro possível limite que superamos foi em relação ao espaço. 0 Memorial da Resistência é uma instituição empenhada na preservação das 
memórias da resistência em relação à repressão política no Brasil republicano. Por isto fica localizado no prédio do antigo Departamento Estadual de Ordem Política e Social de São Paulo - Deops/SP. Realizar a exposição neste espaço foi algo bastante representativo porque consideramos que a presença indígena na atualidade em São Paulo é uma resistência histórica às tentativas de exclusão, como analisamos ao longo deste texto.

O UOL assim destacou esta dimensão:

"Ser essa terra: São Paulo cidade indígena" é a primeira exposição realizada pelo Memorial da Resistência de São Paulo sobre o tema e tem como recorte o território da cidade de São Paulo e a luta empreitada pelos diversos povos - originários, migrantes e seus herdeiros - pela própria existência (UOL, 25/11/2019).

Acredito também que a exposição repercutiu positivamente entre os visitantes em geral porque possibilitou o contato com um olhar indígena sobre ser Índio e acerca da cidade de São Paulo. A duração da exposição é um indicativo neste sentido. Inaugurada em 24 de novembro de 2018 estava programada para terminar em 22 de abril de 2019. Contudo, o grande número de visitantes conduziu à prorrogação até 22 de julho de 2019.

Vivenciar com outros indígenas nosso protagonismo na montagem desta exposição me fez ter mais clareza de que os Povos Originários são os sonhos e as utopias do passado, presente e futuro. Talvez por isto as tentativas de nos silenciar e invisibilizar, como ocorre na cidade de São Paulo e na história brasileira. Porém, parafraseando o título da exposição: "Somos essa Terra: São Paulo é sim indígena, assim como o Brasil". 
Espaço Ameríndio

\author{
"yapy amanapipi \\ okyra, yba, ybyrapó \\ robaca paraña \\ robaca ybaka \\ nheypyrunga bebé \\ ybyuamana moakyma \\ manó paraña \\ obaitî ybaka \\ yjara erecoara \\ yecobé" \\ (Casé Angatu) $^{8}$
}

\author{
AIÊNTÊN !!! \\ AWÊRÊ !!!
}

\footnotetext{
8 "Orvalho a gotejar / folhas, caules, raízes / viram mar / viram céu / reiniciam a voar / ar molhar / onde o mar / encontra o céu / mãe das águas cuida / da Água Vida" (Casé Angatu OBS: esta "tradução" não é ao pé da letra e sim uma interpretação)

SANTOS, Carlos José Ferreira dos. "Ser essa terra: São Paulo cidade Indígena": exposição no memorial da resistência trata da (re)existência dos povos originários na capital paulista. Espaço Ameríndio, Porto Alegre, v. 14, n. 1, p. 118-137, jan./jul. 2020.
} 
Espaço Ameríndio

\section{Referências bibliográficas}

ALMEIDA, Maria Regina Celestino de. Metamorfoses indigenas. Identidade e cultura nas aldeias coloniais do Rio de Janeiro. Rio de Janeiro: Prêmio Arquivo Nacional de Pesquisa, 2003

. Os índios na história do Brasil. Rio de Janeiro: Editora FGV, 2010.

ANGATU, Casé. Anga e TUPINAMBÁ, Ayra (SANTOS, Vanessa Rodrigues). Decolonialidades Indígenas. In: Frederico Alves Costa e Marcos Ribeiro Mesquita. (Org.). Psicologia Política no Brasil e enfrentamentos a processos antidemocráticos v. 01. ed.Macéio: Edufal - Editora da Universidade Federal de Alagoas, 2019a, p. 231241.

Anga Moronguetá - Indigenamente Resistimos porque (Re)Existimos

Originariamente. In: Revista Têmpera. Disponível em: https://issuu.com/grupotempera/docs/revistatempera_3_2019?fbclid=IwAR2ZbmKkCyI uIKgwGI0YSe5JtQAtcrMSAnpgFWBL0genWXaTzKd8ttf5zBE, Acesso em: 02/03/2019b.

. e TUPINAMBÁ, Ayra (SANTOS, Vanessa Rodrigues). Terrorismo de Estado e lutas indígenas: (re)existências indígenas e indianidades, enfrentando 517 anos de ditaduras!. In: PITTA, Fábio Teixeira; MARIANA, Fernando Bomfim; BRUNO, Lúcia Emília N. B.; SILVA, Rodrigo Rosa da (Orgs.). Terrorismo de Estado, Direitos Humanos e Movimentos Sociais. São Paulo: Entremares, 2018a.

. e TUPINAMBÁ, Ayra (SANTOS, Vanessa Rodrigues). Protagonismos Indígenas: (re)existências indígenas e indianidades. In: Maria Luiza Tucci Carneiro e Mirian Silva Rossi. (Org.). Índios no Brasil: Vida, Cultura e Morte. 1ed.São Paulo: Editora: Intermeios Cultural e Co-Edição: LEER-USP e IHF, 2018b, p. 23-40.

. Frases: Exposição Ser Essa Terra: São Paulo Cidade Indígena. São Paulo: Expostas e Painéis da Exposição Ser Essa Terra: São Paulo Cidade Indígena, 2018c.

Entrevista: Nós não somos donos da terra, nós somos a terra. In: Revista IHU On-Line, intitulada Ore Ywy - A necessidade de construir uma outra relação com a nossa terra - Edição 527. Porto Alegre: Instituto Humanitas Unisinos, Disponível em: http://www.ihuonline.unisinos.br/artigo/7395-nos-nao-somos-donos-da-terra-nossomos-a-terra, Acesso em 27/08/2018d.

(SANTOS, Carlos José F.). Nem Tudo Era Italiano - São Paulo e pobreza na virada do século XIX-XX (1890-1915). São Paulo: Annablume/FAPESP, (4a. Edição) 2017a.

Cartas Indígenas. In: GALINDO, Dolores, PEREIRA, Maristela de S. RASERA, Emerson F., (Organizadores). Democracia Participativa, Estado e 
Espaço Ameríndio

Laicidade: Psicologia Social e Enfrentamento em Tempos de Exceção. São Paulo: ABRAPSO, 2017b.

. História e Culturas Indígenas - Alguns Desafios no Ensino e na Aplicação da Lei 11.645/2008: De Qual História e Cultura Indígena Estamos Falando?. In: Revista História \& Perpectiva do Núcleo de Pesquisa e Estudos em História, Cidade e Trabalho do Curso de Graduação e Pós-Graduação em História da Universidade Federal de Uberlândia-UFU. Uberlândia: UFU, 2015.

. (SANTOS, Carlos José F.). Identidade Urbana e Globalização - a formação dos múltiplos territórios em Guarulhos/SP. São Paulo: Annablume/SINPRO-Guarulhos, 2008.

ARRUTI, José Maurício Andioni. Morte e vida do nordeste indígena: a emergência étnica como fenômeno histórico regional. In: Estudos Históricos - vol. 8, n. 15. Rio de Janeiro: 1995.

De como a cultura se faz política e vice-versa: Sobre religiões, festas, negritudes e indianidades no Nordeste contemporâneo". In: IV Ciclo NAÇÃO E REGIÃO - Brasil 500 anos. Rio de Janeiro: FUNART/UERJ/UENF, 2002.

AYRA Tupinambá (Vanessa Rodrigues) e ANGATU, Casé (Carlos José F. Santos). Decolonialidades indígenas. In: COSTA, Frederico Alves, MESQUITA, Marcos Ribeiro Mesquita (Orgs.). Psicologia política no Brasil e enfrentamentos a processos antidemocráticos. Maceió: Edufal, 2019a. p. 231-242.

(Vanessa Rodrigues) e ANGATU, Casé (Carlos José F. Santos). Tupinambá Protagonismos Indígenas: (Re)Existências Indígenas e Indianidades. In: CARNEIRO, Maria Luiza Tucci e ROSSI, Mirian Silva (Orgs.) Índios no Brasil: Vida, Cultura e Morte. São Paulo: IHF; LEER/USP; Intermeios 2018a. p. 23-40.

BALLESTRIN, Luciana. América Latina e o giro decolonial. In: Revista Brasileira de Ciência Política, $\mathbf{n}^{\mathbf{0} 11}$. Brasília: UnB, maio - agosto de 2013, pp. 89-117.

BRAH, Avtar. Cartografías de la diáspora. Identidades em cuestión. London: Traficantes de Sueños, 2011.

CALEFFI, Paula. O que é ser índio hoje? A questão indígena na América Latina/Brasil no início do século XXI. In: Diálogos Latinoamericanos, V. 007. Dinamarca: Universidad de Aarthus, 2003: p. 20-42.

CASTRO, Eduardo Viveiros de. No Brasil, todo mundo é índio, exceto quem não é. In: RICARDO, Beto Ricardo e RICARDO, Fany. Povos Indígenas no Brasil 2001/2005. São Paulo: Instituto Sócio Ambiental, 2006.

. A indianidade é um projeto de futuro, não uma memória do passado. In: Prisma Jurídico. v. 10, n. 2. São Paulo: Prisma Jurídico, jul./dez. 2011, p. 257-268. 
Espaço Ameríndio

CASTRO-GÓMEZ, Santiago \& GROSFOGUEL, Ramon (Coords.) El giro decolonial: reflexiones para uma diversidad epistêmica más allá del capitalismo global. Bogotá: Siglo del Hombre Editores, Universidad Central, Instituto de Estudios Sociales Contemporáneos, Pontificia Universidad Javeriana, Instituto Pensar. 2007.

CUNHA, Manuela Carneiro da. (org.) História dos Índios no Brasil. São Paulo: Companhia das Letras. Secretaria Municipal de Cultura: FAPESP, 1992.

Enigma, 2012.

Índios no Brasil: história, direitos e cidadania. São Paulo: Claro

Etnicidade, da cultura residual mas irredutível. In: Cultura com aspas, e outros ensaios. SP. Ed. Cossac Naif, 2009.

O futuro dos índios: entrevista com Manuela Carneiro da Cunha. In: O Globo. Disponível em: http:/oglobo.globo.com/blogs/prosa/posts/2013/02/16/o-futurodos-indios-entrevista-com-manuela-carneiro-da-cunha-486492.asp, Acesso em $16 / 02 / 2017$.

FANON, Frantz. Os condenados da Terra. Juiz de Fora. Editora UFJF. 2010.

GOMA OFICINA. Ser Essa Terra: São Paulo Cidade Indígena | Memorial Da Resistência. Disponível em: https:/gomaoficina.com/projetos/ser-essa-terra-sao-paulocidade-indigena-memorial-da-resistencia/ Acesso em: 24/10/2019

GROSFOGUEL, Ramón. Para descolonizar os estudos de economia política e os estudos pós-coloniais: transmodernidade, pensamento de fronteira e colonialidade global. In: Revista Crítica de Ciências Sociais, n. 80, 2008. p. 115-147.

A estrutura do conhecimento nas universidades ocidentalizadas:

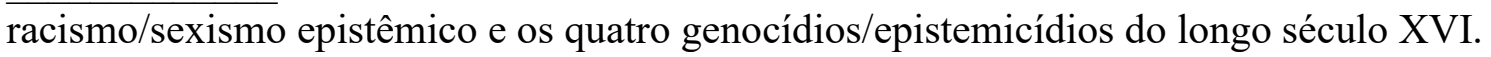
In: Revista Sociedade e Estado - Volume 31 Número 1. Brasília: UnB - Instituto de Ciências Sociais - Campus Universitário Darcy Ribeiro, janeiro/abril 2016.

LANDER, E. (Org.). A colonialidade do saber: eurocentrismo e ciências sociais. Perspectivas latino-americanas. Buenos Aires: Clacso, 2005

MEMORIAL DA RESISTÊNCIA. Sobre o Memorial da Resistência. Disponível em: $\mathrm{http}: / / \mathrm{memorialdaresistenciasp.org.br} / \mathrm{memorial} / \mathrm{default}$.aspx $\mathrm{mn}=4 \& \mathrm{c}=83 \& \mathrm{~s}=0$, Acesso em: 24/10/2019.

MIGNOLO, Walter. A colonialidade de cabo a rabo: o hemisfério ocidental no horizonte conceitual da modernidade. In: LANDER, E. (Org.). A colonialidade do saber: eurocentrismo e ciências sociais. Perspectivas latino-americanas. Buenos Aires: Clacso, 2005.

MONTEIRO, John Manuel. Negros da Terra. Índios e Bandeirantes nas origens de São Paulo São Paulo: Cia das Letras, 1995. 
Espaço Ameríndio

. Tupis, Tapuias e Historiadores: Estudos de História Indígena e do Indigenismo. Campinas: Tese Apresentada para o Concurso de Livre Docência Área de Etnologia, Subárea História Indígena e do Indigenismo - Antropologia UNICAMP, 2001.

OLIVEIRA, João Pacheco de. (org.) A Viagem da volta: etnicidade, política e reelaboração cultural no nordeste indígena. $2^{\mathrm{a}}$ ed. LACED, 2004.

; FREIRE, Carlos Augusto da Rocha. A presença indígena na formação do Brasil. Brasília: Ministério da Educação, Secretaria de Educação Continuada, Alfabetização e Diversidade; LACED/Museu Nacional, 2006.

. Três Teses Equivocadas Sobre o Indigenismo (em especial sobre os índios do Nordeste). In: ESPÍRITO SANTO, Marco Antônio do (Org.). Política Indigenista: Leste e Nordeste brasileiros. Brasília: FUNAI/DEDOC, 2000.

PAULA, E. Simões. Contribuição monográfica para o estudo da segunda fundação de São Paulo. São Paulo, s/ ed. 1936

SANTOS, Boaventura de Sousa \& MENESES, Maria Paula (Orgs.). Epistemologias do Sul. São Paulo: Cortez, 2010.

SPIVAK, Gayatri Chakravorty. Pode o Subalterno Falar?. Belo Horizonte: Editora UFMG, 2010.

UOL, Opera Mundi. "Ser essa terra: São Paulo cidade indígena" no Memorial da Resistência. In: UOL. Disponível em: https://dialogosdosul.operamundi.uol.com.br/permalink/54078, Acesso em: 25/11/2019.

WALSH, Catherine (Org.). Pedagogías decoloniales: prácticas insurgentes de resistir, (re)existir y (re)vivir. Quito, Ecuador: Ediciones Abya-Yala, 2013.

. Interculturalidade Crítica e Pedagogia Decolonial: in-surgir, re-existir e re-viver. In: CANDAU, Vera Maria. Educação Intercultural na América Latina: entre concepções, tensões e propostas. Rio de Janeiro: 7 Letras, 2009. 